\title{
Ramais de tradução: Diário do hospício e outros escritos de Lima Barreto
}

\author{
Sidnei Sousa Costa ${ }^{1}$ \\ Sidney Barbosa ${ }^{2}$
}

\begin{abstract}
Resumo: Este artigo tem como objetivo identificar aspectos da tradução em alguns escritos de Lima Barreto. Para proceder nossa análise realizamos a leitura de diferentes textos do autor, dos quais recortamos uma parte do Diário do Hospício (1961), Correspondência Ativa - Tomo I (1961) e outras crônicas do autor em questão. Destacamos desses textos as notas de um leitor escritor que partilha com seus interlocutores sua visão sobre narrativas que passam à sua mão. Por isto, a perspectiva será apontar os escritos e tecer sobre eles comentários que possam colaborar com a construção de uma visão do Lima Barreto leitor, tradutor e intérprete do texto alheio, identificando, desta forma, infuências e referências, pelas quais o autor empenhou sua escrita ou procurou distanciá-la.
\end{abstract}

Palavras-chave: Lima Barreto, tradução, outras leituras.

\section{Escritos iniciais}

Sonhei Spinoza, mas não tive força para realizar a vida dele; sonhei Dostoiévski, mas me faltou a sua névoa. (BARRETO, 2010, p. 94)

Na língua portuguesa a palavra "ramal" remete a uma infinidade de definições, a depender do contexto em que esteja empregada. A acepção desse vocábulo tem aqui como linha a referência aos circuitos secundários que podem desembocar em uma

1 Mestrando em Literatura (POSLIT/UnB). E-mail: sidneics@gmail.com

2 Professor Adjunto de Literatura Francesa e Teoria Literária da UnB. E-mail: sidneyb@unb.br 
direção principal remetendo-se a uma das definições presentes no Dicionário Houaiss da Língua Portuguesa (2001). A direção das discussões propostas neste texto tem como finalidade reconfigurar os circuitos de linguagem narrativa que caracterizam os escritos e leituras que apresentem Lima Barreto como um tradutor.

A tradução é parte do arcabouço literário do autor, faz-se perceptível em diferentes textos seus e contextos em que esteve envolvido, como se observará na discussão proposta nesta análise. Barreto empenhou-se na leitura de distintas narrativas em alemão, francês, inglês e português, valendo-se de diários para rememorar as passagens que mais lhe marcavam. Nas cartas, partilhou com seus pares mais próximos suas impressões das leituras que que realizava, ampliando esse diálogo com aqueles que o acompanhavam, pelas crônicas publicava em diferentes periódicos da capital carioca.

A relação do autor com as línguas estrangeiras vem do colo paterno, pois seu pai, João Henriques Barreto, detinha uma afeição pela leitura que foi transmitida ao filho, que desde bem jovem Lima Barreto foi presenteado pelo pai com textos clássicos, em vernáculo e em línguas estrangeiras. João Henriques lembrava ao filho o papel importante das edições e dos textos que lhe passava às mãos, dos quais apresentaremos alguns exemplos para levar adiante esta discussão. Parte desses fatos foram rememorados pelo autor em diferentes passagens de seus textos, construídas por vezes de forma direta, noutras com elaborações que remetem à sua vida.

Podemos afirmar que João Henriques foi o precursor da família Barreto no exercício da tradução, pois, tipógrafo de profissão, traduziu do francês o Manual do aprendiz compositor de Jules Claye 3 . (ASSIS, 2003, p. 51). Além disso, devido à importância que creditava à educação, João Henriques empenhou-se em garantir ao filho um ensino que lhe desse base alcançar caminhos mais audaciosos, como tornar-se doutor, sonho que o pai não conseguiu realizar.

Lima Barreto estudou em escolas públicas de excelente qualidade em sua infância, privilégio esse que reverenciou em suas narrativas. Numa passagem, rememora o orgulho que seu pai teve ao vê-lo receber um prêmio na escola: um belo volume encadernado e com gravuras de As grandes invenções, de Luis Liguier, com dedicatória de D. Teresa Pimental Amaral (ASSIS, 2003, p. 67). Preocupado em garantir que o filho tivesse um destino na escola diferente do seu João Henriques procura ajuda de seu

3 Assis (2003) destaca que não se trata de um simples manual, mas um texto que se divide entre as lições do famoso tipógrafo, com recortes de passagens de Machado de Assis que simbolizavam esse ofício e lembra a forma tipográfica de compor poesias em português. Trata-se de um dos mais importantes manuais da área, que serviu de referência aos iniciantes da tipografia na Imprensa Nacional por um período considerável. 
compadre, o Visconde de Ouro Preto. O padrinho, então, custeou a educação do afilhado, matriculando-o no Liceu Popular Niteroiense, destacada instituição da época, onde Lima Barreto convivera com figuras que, mais tarde, se destacariam pela escrita em jornais, na magistratura, na carreira das armas e no magistério.

O autor concluiu o curso secundário em 1984 no Liceu, onde teve suas primeiras aulas de inglês com Miss Annie, com quem trocou dezenas de cartas. Também havia dois outros professores de quem recebia muita atenção, o professor, o professor de história Chico Varela e Frutuoso da Costa, professor de Francês e Latim. Esse era negro, mineiro, que estudou para ser padre, mas acabou não se ordenando (ASSIS, 2003). Inclusive, esse mestre fora personagem na narrativa Recordações do Escrivão Isaías Caminha (1961) e em uma das crônicas de Bagatelas (1961), na qual assim o descreve:

O doutor (assim o tratávamos) Frutuoso da Costa, um deles era o preto mineiro, que estudara para padre e não chegara a ordenar-se. Tudo nele era desgosto, amargor; e às vezes, deixávamos de analisar a Seleção, para ouvirmos de sua feia boca histórias polvilhadas dos mais atrozes sarcasmos. Os seus olhos inteligentes debaixo de seus pince-neze o seu sorriso de remoque mostrava os seus dentes de marfim de um que não me atrevo a qualificar. O seu enterro saiu de uma quase estalagem. (BARRETO, 1961, p. 62)

As formas de narrar desses professores desperta em Lima Barreto a curiosidade de explorar os diferentes contextos de se contar histórias. O autor reconstrói uma dessas passagens em Isaías Caminha e remonta a uma de suas memórias de infância, lembrando-se da aula de Virtuoso que, ao perceber a forma descompromissada de leituras de alguns alunos, chamava atenção deles, retirando seus óculos, tomava o seu exemplar do Thêatre Classique e recitava trechos da tragédia bíblica de Racine, declamando-os com muito entusiasmo, em francês.

Lima Barreto reconstituíra esses percursos e os destacara nos recortes propostos em seu diário, nas cartas e no que se intitulou outros textos, com trechos de crônicas que atestam a existência do interprete, do leitor e, por fim, do tradutor que configura em suas leituras as narrativas que lhe provocaram reflexão.

\section{Ramais de tradução no Diário do Hospício}

O Diário do Hospicio é uma narrativa concebida a partir de notas que o autor tomou após sua segunda passagem pelo Hospício Nacional de Alienados, na Praia Vermelha, no Estado do Rio de Janeiro. Trata-se de um texto de memórias 
que pretende abrir o hospício para aqueles que nunca estiveram presentes naquele espaço. Em tiras de papel e em papeis inteiros (BARRETO, 2010, p. 42) o autor descreve as pessoas que estavam dividindo com ele aquela experiência do cuidado para a cura da loucura ou do alcoolismo, os distintos espaços hospitalares e os comportamentos dos profissionais da saúde que ali atuavam. Seus pares naquele espaço, tal como acontecia com ele, passavam por crises alternadas de delírio e de sobriedade, forneciam-lhe diferentes histórias, algumas merecedoras de registro e outras que evidenciavam simplesmente o desvario, espécie de resposta àquele mundo sufocante e equivocado no tratamento dispensado aos pacientes. Lima Barreto traduzia essas falas e acontecimentos em textos plenos de afeto e compaixão por si mesmo e pelos outros participantes daquele local tido como curativo e equilibrador, mas que, na realidade, tinha pouco êxito nesse intento.

A localização do Hospício Nacional era privilegiada, com uma vista para o mar no edifício superior, onde estava situada a biblioteca, o que possibilitava aos seus frequentadores ver, pelas brechas das grades, os navios passarem de um lado para outro, ora atracando no porto, ora ganhando os mares rumo a outros continentes. Esses movimentos aguçavam a observação de Lima Barreto, que buscava nos livros alcançar os locais onde essas naus encontravam novas pessoas, histórias e culturas. Ele não conseguiu atravessar o mar e conhecer outros países, fato esse que fora descrito e pode ser observado tanto na memória do autor, quanto no Diário Íntimo (1961), em que imprime suas angústias e felicidades, dentre as quais a impossibilidade de partilhar da experiência de conhecer o exterior. Essas terras longínquas, Barreto pode conhecer por meio do texto narrativo de Jules Verne que, segundo ele, o enchia de melancolia e de sonhos. As edições das viagens fantásticas fora um dos primeiro presentes que Lima Barreto ganhou de seu pai na infância. Ele rememora o contato com essa leitura e o que ela lhe provocara:

Não gostava muito das viagens fantásticas, como à lua, ou que tivessem, por entrecho uma coisa inverossímil, como no País das peles; assim mesmo apreciava o César Cascabel a Viagem ao centro da Terra. Do que mais gostava, eram aqueles que se passavam por regiões exóticas, como a Índia, a China, a Austrália; mas, de todos os livros, o que mais amei e durante muito tempo fez o ideal da minha vida foram as Vinte mil léguas submarinas. Sonhei-me um capitão Nemo, fora da humanidade, só ligado a ela pelos livros preciosos, notáveis ou não, que me houvessem impressionado, sem ligação sentimental alguma no planeta [...] (BARRETO, 2010, p. 103)

A extensa obra produzida por Lima Barreto traduz à perspectiva de Cuti (2011) como espaço de multiplicidade de abordagens, seja nos seus registros de 
memória, nas narrativas e até nas crônicas diárias, impressas nos diferentes periódicos do Rio de Janeiro, que demarcam passagens de um tempo de transformação social, racial e política daquele momento histórico. Assim, a escrita de Barreto traz figuras típicas, políticos, personagens comuns, como também os próprios loucos do Diário do Hospício ou revolucionários como o personagem Policarpo na narrativa Triste Fim de Policarpo Quaresma (1996). Nas narrativas indicadas, verifica-se que Barreto fez questão de apresentar os textos que chegaram em suas mãos aos leitores, sejam seus editores, com quem mantinha uma troca ativa de cartas e opiniões, sejam os leitores seus leitores dos jornais que colaborava. É dentro desses ramais que se identificam os textos que mais chamavam atenção do autor, incluindo-os nos diários ou ressaltando a ausência deles nas bibliotecas pelas quais passava. Uma das pretensões desse trabalho é recuperar junto à memória narrativa de Barreto os textos que ele traduziu, que são demarcados por sua escrita enquanto leitor, memória essa transcrita nos elementos de sua passagem pelo hospício, principalmente pelo ressentimento do que mais sentia falta naquela estada: parte de seus livros, a rua com as suas surpresas, as alegrias e a tristeza de sua casa.

Ao adentrar o hospício e passar pelos ritos vexatórios de limpeza que o local impunha aos seus internos, Barreto inicia a série de referências literárias às suas leituras pregressas. Os internos eram obrigados a se despir na frente de outras pessoas e dos enfermeiros e forçados a tomar um banho público. Essa tentativa de limpeza, como rito de passagem, trouxe à memória do autor o banho a vapor que Dostoiévski descreveu em Casa dos Mortos, que Barreto recupera: "quando me baldeei, chorei; mas lembrei de Cervantes, do próprio Dostoiévski, que piorpoderiam ter sofrido em Argel e na Sibéria" (BARRETO, 2010, p. 46). A imagem do banho propicia diversas correlações, dentre as quais a que o indivíduo precisa passar por uma limpeza, retirar aquilo que não lhe é necessário, porém, nesse momento o autor recupera em sua memória os textos que mais lhe apetecem, o que relativiza a sua angústia e tornava-o solidário, mesmo fora do tempo e do espaço, com autores que admirava.

O espaço da biblioteca torna-se a saída para Barreto encontrar o que estava perdendo com o desequilíbrio que o álcool lhe provocara. Na primeira oportunidade de interlocução com os superiores responsáveis pelo hospício o autor destaca a necessidade de ficar em uma seção mais próxima à biblioteca. Barreto identifica ali um conjunto de obras, inclusive uma de Dostoiévski. Outra obra que lhe chamou muito a atenção é o Dicionário das literaturas ${ }^{4}$ de Vapereau, sobre a qual se

4 Trata-se de uma obra publicada em francês (1876) que reuniu recortes sobre os principais autores que referenciavam a literatura até então. Desta forma, há na obra uma síntese de autores e os escritos que influenciaram a literatura da época. Esta obra foi organizada por Louis Gustave Vapereau. 
debruçava numa leitura prazerosa. Há também nesse espaço livros curiosos: livros sobre finanças de Colbert, Feliz Jousseaume e Histoire des Classes rurales en France et de leurs progrès dans l'égalité civile et la proprieté (1857) de Henri Doniol (BARRETO, 2010 , p. 102) e outros que, segundo ele, não seria possível ler por completo, talvez pelo tempo ou pelo próprio conteúdo.

Apesar de se sentir bem na biblioteca, Lima Barreto passou a se incomodar com alguns de seus pares que perturbavam sua concentração, com suas perguntas ou divagações, enumerações e qualificações dos médicos, fazendo com que tivesse que interromper suas leituras. Resolve então alternar as manhãs, por vezes lendo na biblioteca, noutras no quarto em que ficou durante a internação. Em seu recinto a leitura era Plutarco, e a ela se refere:

A minha leitura atual desse celebre livro é feita com outro olhar que o de antigamente. Noto-lhe uma porção de atributos sempre os mesmos, para os seus heróis. Ele os quer sempre belos, como filhos mais belos de seu tempo, e o paralelo entre os heróis da Grécia e Roma, às vezes, não é feliz; há sempre nele muita coisa que nos faz refletir. Vejam só esta observação de um antepassado dos atuais bolchevistas, do citado Anacársis, feita a Sólon: "As leis são como teias de arranha que prendem os fracos e pequenos insetos, mas são rompidas pelos grandes e fortes". (BARRETO, 2010, p. 104)

No texto nota-se a interlocução do autor com a narrativa clássica e o momento por que passava o país. Barreto nasceu no curso da libertação dos escravos, em sua juventude esteve imerso no contexto de afirmação da República.

Na passagem do autor pelo hospício, apesar de parecer um local não propício à reflexão, identifica-se nessas memórias um leitor obstinado pelo contato com o pensamento alheio. Esses são aspectos destacados nos recortes que demarcam um Lima Barreto que buscava na biblioteca as edições clássicas, que possibilitavam que ele dialogar e trazer a realidade de outras localidades para a efervescência da nascente república brasileira.

Por isso, é importante trazer à baila as cartas que, apesar de não terem sido escritas no hospício, contextualizam a necessidade de diálogo de Barreto com autores estrangeiros, autores estrangeiros e editores, como Monteiro Lobato, por exemplo, que dialogavam com ele no processo de construção de suas narrativas. 


\section{Ramais de tradução em correspondência ativa}

Francisco Assis Barbosa ${ }^{5}$ (2003) empenhou-se na historiografia literária e tornou-se um nome de referência nessa área. Dentre suas colaborações, destaca-se a organização da obra de Lima Barreto. O empenho do biógrafo foi uma resposta, há três décadas, aproximadamente, em que a produção barreteana quase foi esquecida. Nas obras completas de Lima Barreto, editadas em 1956, identifica-se a edição das Correspondência Ativa - Tomo I (1961), onde constam cartas que Barreto partilha com seus pares, inquietações, propostas de textos e a sua leitura dos livros que mais lhe chamavam atenção. Nessas cartas percebe-se seu lado leitor, que não deixa passar incólume a sua crítica sobre a visão de Brasil apresentada em livros. Em uma das cartas a M. T Gomes Carneiro ${ }^{6}$, Barreto partilha as impressões sobre a leitura dos Anais que Tácito escreveu sobre os imperadores:

(...) Sabes? Li o Tácito, o Suetônio, o César; o primeiro em português, os dois últimos em francês. Tinha-os em casa desde muito e só agora me deu vontade de lê-los. Meto-me agora no Heródoto. Como estás vendo, estou clássico, mas em francês. Isso não vem ao acaso, ou antes, vem porque explica o pedido que te vou fazer. O Calígula me apaixona. Que homem! É uma maravilha. Os compêndios caluniam-no. Com as suas ideias de mestre de escola, estragaram-me por muito tempo o personagem, porque Caio não é homem, Carneiro, é um personagem, é coisa criada pelos homens, não por suas letras, mas pelas suas ideias de certo tempo e instituições. É um Rabelais vivo; é um profundo e largo deboche a um tempo e a uma época. (BARRETO, 1961, p. 126)

Na seleção de cartas, percebe-se o Lima Barreto leitor que se propõe a dialogar com a tradição hermenêutica, pois passa da interpretação à tradução de textos. No excerto da carta do autor a um seu contemporâneo, é possível observar "o processo interpretativo em uma busca de interpretação da palavra alheia” (ECO, 2007 , p. 270). Nota-se, portanto, o empenho de Barreto no diálogo com os textos alheios que, em parte, denotam aspectos que se nota em sua contemporaneidade,

5 Foi jornalista, biógrafo, historiador, ensaísta e membro da Academia Brasileira de Letras (1914-1991). Natural de Guaratinguetá estado de São Paulo. A obra de Assis Barbosa evidencia-se pelo rigor e pela interpretação. Escreveu sobre a vida e compilou toda a obra de Lima Barreto. Empenhou-se também em escrever sobre os assuntos e problemas brasileiros, entre a política e as questões sociais.

6 Mario Tibúrcio Gomes Carneiro (1904-1914), jurista que conheceu Lima Barreto à época que cursava a Faculdade de Ciências Jurídicas. Eles frequentaram juntos a Federação dos Estudantes. Fundou o grupo Floreal, mas logo abandona a Literatura para dedicar-se aos estudos de Direito. 
a ponto de provocar a reflexão de seu par por meio do diálogo na troca dessas comunicações. Desta forma, o esforço de Barreto no transcurso de sua leitura eleva a inspiração provocada pelo texto em que se debruçava, assentando ainda os seguintes aspectos:

(...) Foi Boissier quem, falando de Adriano, me lançou grande luz no espírito sobre o modo de compreender os imperadores romanos; aquele poder soberano, equivalente, no tempo, a de um deus, sem caráter preciso, sem limite fixo, aquela vertigem que produzia o medo e orgulho - tudo isso me fez estudar melhor o Caio César - ou melhor: Calígula. (Idem, p. 126)

Ao estabelecer a indicação ao outro sobre o entendimento de um texto, Barreto entra em um contexto distinto. $\mathrm{O}$ autor caminha, portanto, para a construção de metáforas e criando diferentes matérias sobre o texto lido. No diálogo com seu interlocutor, entra em outra acepção e demonstra os signos que permeiam seu entendimento sobre o contexto proposto.

Segundo Eco (2007, p. 275) é importante observar o sentido etimológico no entendimento entre a tradução e a interpretação, para não incorrer na limitação das interpretações possíveis ao texto. Assim, para demarcar esses pontos que possibilitam a ampliação do olhar sobre a discussão proposta, é interessante trazer ao texto os seguintes aspectos:

Em latim, o termo translatio aparece incialmente no sentido de "mudança", mas também de "transporte", passagem bancária de dinheiro, enxerto botânico, metáfora. Somente em Sêneca que aparece como uma versão de uma língua para outra. Da mesma forma, traducere significava "conduzir" ao além. Mas é bom lembrar que também na idade média se falava de tranlatio imperii como, justamente transporte, passagem da autoridade imperial de Roma para o mundo germânico. (ECO, 2007, p. 275)

Está aí demonstrada a interlocução proposta por Barreto a Carneiro, transmitindo-o sua versão de entendimento sobre os imperadores romanos. Mais adiante, na mesma carta, questiona sobre o entendimento do amigo em relação àquela leitura, na perspectiva de alcançar uma passagem sobre o texto proposto. Noutra carta, esta direcionada a O. A. Inglês de Sousa ${ }^{7}$, identifica-se a reflexão do autor sobre o gênero carta. Trata-se de uma passagem interessante, pois demonstra

7 Otávio Augusto Inglês de Souza era sobrinho do romancista Inglês de Souza, estudou na Escola Politécnica do Rio de Janeiro, onde conheceu Lima Barreto. Desenvolveu vasta reflexão sobre a filosofia. 
que Barreto tratava esse exercício com cuidado, pois sabia que, nas entrelinhas de seus escritos, haviam pensamentos distintos e impressões de leitura:

Escrever uma carta é para mim um sacrifício. É um gênero de literatura que não conheço, ou antes, em que ainda não percebi bem a medida. Várias vezes tenho ensaiado com os amigos que estão fora. Escrevo uma sai-me cheia de "histórias", de efes e erres, pedante em suma, rasgo. Tento outra, acabada que é, leio-a; acho desfrutável, cheia de efusões de sentimentalidade. Depois (já eu queria escrever uma teoria da carta!...). (BARRETO, 1961, p. 145)

Ávido leitor, Lima Barreto fora sempre muito atento ao que se passava à sua volta. Por meio das cartas, estava permanentemente em interlocução com seus amigos e boemia, da escola e dos editores, que lhe enviaram edições de livros de suas viagens. Isto mantinha em Barreto o interesse pelas novidades literárias e artísticas que estavam em voga na Europa e, principalmente, o tema das conversas nos cafés franceses. Como exemplo podemos citar, ainda se tratando de Correspondência: ativa e passiva. $1^{\circ}$ tomo (1961), a carta do autor dirigida a C. Bouglé $e^{8}$, na qual explicita seu incômodo sobre o desconhecimento que aquele sociólogo demonstrava em sua obra sobre os afrodescendentes brasileiros, na carta tratados de mulatos:

Je vous écris, Mr., plein d'audace, au sorti de la lecture de votre livre - La Démocratie devant la Science. Croyant que vous pardonnerez mes fautes de français, cette a pour but offrir des renseignments sur l'activité des mulatres dans mon pays.

Je suis mulatre aussi, jeune, 25 ans, ayant fait mes études a l'École Polytecnhique Je suis mulâtre, laissant de continuer mon cours (génie civile) pour me rendre à la littérature de Rio, où je suis redacteur de deux petites revues de Rio, où je suis né, et employé au Bureau de la Guerre [ilegível].

Lisant votre beau livre, j’ai observé que vous êtes au courant des choses de I'Inde et que vous savez sur les mulâtres du Brésil. Dans les Lettres brésilennes, déjá remarquables, les mulâtres ont eu une grande representation. Le plus grand poète nacional, Gonçalves Dias, était mulâtre; le plus savant musicien, sorte de lastreine, José Maurício, était mulâtre; les grands noms actuels de la littérature - Olavo Bilac, Machado de Assis et Coelho

8 Célestin Bouglé (19870-1940), sociólogo francês, discípulo de Durkheim, foi professor de Sociologia na Sorbonne. Escreveu dentre outros livros: La Déemocratie devant la Science (1904); Leçons de Sociologie sur l'evolution des valeurs (1922). 
Neto sont des mulatres. Le courant mulâtre dure il y a un siécle et demi, depuis Caldas Barbosa (1740-1800) et Silva Alvarenga (1749-1814) (...). [sic] (BARRETO, 1961, p. 159)

Nesta carta é possível observar a preocupação de Lima Barreto, expressa de forma contundente aos seus próprios contemporâneos, inclusive àqueles que ele resguarda duras críticas, como Coelho Neto e Machado de Assis. Ressoa, portanto a pretensão de preencher as lacunas do estudioso sobre os negros do Brasil, falando do outro lado do continente. Esses registros demarcam um autor em constante articulação em meio ao processo criativo de diálogo com o outro. Para ele, até simples cartas abrem reflexões, ampliam os horizontes de leitura e de conhecimento, possibilitando, desta forma, aproximações e distanciamentos sobre a forma de traduzir e interpretar as colaborações ditas como alheias.

Nossa proposta da leitura deste aspecto em Barreto é deixar claro o entendimento de que ele mantinha diálogos com a escrita estrangeira e que, no contato com o que está proposto pelo sociólogo francês como sendo um retrato de Brasil, foram identificadas por ele incoerências e desconhecimento de elementos importantes, como a condição do negro no Brasil, visto de uma maneira depreciativa. O autor deixava claro que não concordava com opiniões levianas por parte de pessoas que se propunham a escrever sobre uma localidade que desconheciam, além de estarem do outro lado do Atlântico. A carta de Barreto demonstra o leitor ávido e comprometido que era, que traduz o texto lido para a sua realidade e que demarca sua discordância com o que considerava serem incoerências graves sobre a situação do negro em seu país.

A partir desta e de outras interlocuções pode-se abrir o caminho de análise do intertexto presente nas narrativas do autor. Esse aspecto será demonstrado a seguir, na parte em que são apresentados os recortes de tradução na obra de Barreto.

\section{Ramais em outros escritos: a tradução}

Convinha, disse ele, que precedendo estes meus comentários justificasse como eu, modesto privat Dozent de uma universidade alemã, atrevi-me a comentar obras de autor desse longínquo Brasil. Desde moço, pois tenho meus quarenta e cinco anos de idade, dediquei-me ao estudo grotesco e do ridículo sobretudo, e essa face das cousas humanas levou-se a pesquisas dos seus tipos mais notáveis, os quais com consciência observei e analisei. (BARRETO, 2004, p. 320). 
O excerto destacado acima é uma tradução de carta escrita em alemão pelo professor Adolfo Von Schulze, da Universidade de Freiburg, publicada no jornal $A B$ em 1918, intitulada Cada raça tem um Calino. Trata-se de uma "crítica a um "sábio alemão à biografia do ex-ministro da Justiça, Amaro Cavalcante, escrita por Pelino Guedes" (CORRÊA, 2010, p. 01). A análise proposta por Corrêa parte dessa crítica para construir uma leitura sobre o posto de tradutor, assumido por Lima Barreto de tradutor. Revela, a partir dessa crônica, aspectos da leitura de Barreto presente em outros textos, como Recordações de Isaías Caminha, no contexto da obra afirma tratar-se de memórias escritas em francês e traduzidas por ele.

Essas observações que Corrêa propõe ganham relevo à luz da leitura destacada anteriormente, primeiramente do Diário do Hospicio, seguida das Correspondências, em ambas as quais é possível identificar Barreto como interlocutor com diferentes escritores. Tais diálogos possibilitam seu contato outros escritos, como destacado, em francês, inglês e alemão o autor acessava obras ora por empréstimo ou mesmo por presente dos pares que viajavam mundo a fora. Esses textos dão inclusive substrato e passam a integrar os contornos das crônicas que ele apresenta figuras de percepção autoral.

Lima Barreto demonstra nos textos que foram analisados para esse artigo que a sua leitura ultrapassava o simples recorte e caminhava para um diálogo mais amplo, inclusive com a reconstituição das figuras, perceptível na crônica destacada anteriormente. Percebe-se que o autor, para além da tradução, estabeleceu o diálogo com o convívio dos contemporâneos, nivelando o conteúdo das discussões afeitas à realidade de seus leitores.

A tradução nos escritos barreteanos tem como propósito "trazer para uma determinada língua uma informação que está escrita em outra” (ESTEVES, 2014, p. 75). Esses aspectos são contextualizados nas construções narrativas, fruto do empenho do leitor e autor Lima Barreto. Nota-se que, a partir da leitura dos escritos em outra língua, construiu um conhecimento que ele transmite tanto ao rescrever, como se observa na tradução da carta do professor Adolfo Von Schulze, bem como na releitura que faz de parte do conteúdo de sua tradução por seu personagem Isaías Caminha. Nessa narrativa, chama à atenção a mistura de aspectos deslocados entre a carta que ele resgata na descrição do personagem central de Isaías Caminha, também aproveita para homenagear o seu mestre maior das línguas, o professor Frutuoso da Costa. 


\section{Considerações finais}

Esta análise iniciou-se com os escritos em pedaços de papel que, possivelmente, poderiam ter se perdido com o tempo, porém, Lima Barreto foi um autor que não deixava os verbos fugirem à luz de uma nova ideia. Colocava-a no papel mais próximo e o guardava cuidadosamente.

No transcorrer da análise seguem-se as cartas que, por vezes, estão também registradas em pedaços de papel. Ao longo do tempo puderam vir a formar a formar grandes teias de ideias, de textos e de pensamentos. Por isso, o próprio Barreto reflete sobre esse aspecto e inclui a carta como um gênero ainda a ser percebido com maior grandeza e acuidade. São traços, marcas e heranças de um grande escritor e um personagem único da nossa Literatura.

Lima Barreto "compreendeu ainda jovem que intelectuais pedantes são os funcionários de dissuasão e visando ao consenso da ordem dominante" (SANTOS, 2004, p.105). Desta forma, segundo o autor, essa ordem trabalhava somente para a humilhação dos pobres. Ao trabalhar a hipótese de colocar nas entrelinhas de suas colaborações nos diferentes periódicos, entre os quais o jornal $A B C$, que circulava na capital, na leitura que fazia dos textos em alemão, francês e inglês, Barreto possibilita o contato e a interlocução com as leituras que lhe provocaram reflexão.

Nesse sentido, ao disponibilizar a leitura e traduzir os textos para os jornais de circulação, o autor alinha a perspectiva do intelectual de novo tipo, "livre da ilusão burguesa, que trabalha nos interstícios entre as classes, por um lado, e não na cisão entre classificados e desclassificados" (SANTOS, 2004, p. 105). Ora, a leitura era então um atributo de poucos na nascente república e a leitura em outra língua, então, limitava ainda mais sua perspectiva de alcance. Assim, ao interpretar e traduzir os referenciais presentes nos textos que chegavam às suas mãos, Lima Barreto partilhava o conhecimento adquirido com uma particularidade que seus pares não entendiam, ou seja, a linguagem direta, que se assemelhava à conversa que circundava as rodas de cafés e bares da capital fluminense.

É possível perceber que essas leituras buscam também elevar a obra de Lima Barreto a outro estado de reflexão, por estabelecer um contato de referências a escritos de outras terras, mas que, nas entrelinhas, detinham particularidade e complexidades que perturbavam também os autores e as narrativas brasileiras. 


\section{Referências bibliográficas}

BARBOSA, Francisco de Assis. A Vida de Lima Barreto. Rio de Janeiro: José Olimpo, 2003.

BARRETO, Lima. Correspondência: ativa e passiva. $1^{0}$ tomo. São Paulo: Brasiliense, 1961a. (Obras de Lima Barreto, v. XVI). . Diário intimo. São Paulo: Brasiliense, 1961a. (Obras de Lima Barreto, XIV). - Diário do Hospício e Cemitério dos Vivos. São Paulo: Cosac Naify. 2010. . Recordações do Escrivão Isaías Caminha. São Paulo: Brasiliense, 1961a. (Obras de Lima Barreto, v. I). . Toda crônica: Lima Barreto. Rio de Janeiro: Agir, 2004. v. I. . Triste Fim de Policarpo Quarema. Rio de Janeiro: EDIOURO, 1996.

CORRÊA, Henrique S. Silva. O tradutor Lima Barreto: Análise do texto "Cada raça tem um calino”. X SEL - Seminário de Estudos Literários. Disponível em: http:/ / sgcd.assis.unesp. br/Home/PosGraduacao/Letras/SEL/anais_2010/henriquesergio.pdf CUTI [Luís Silva]. Lima Barreto. São Paulo: Selo Negro, 2011. (Retratos do Brasil). ECO, Umberto. Quase a mesma coisa. Tradução Eliana Aguiar. Rio de Janeiro: Record, 2007. ESTEVES, Lenita Maria Rimoli. Atos de Tradução: ética, intervenções, mediações. São Paulo: FAPESP, 2014.

HOUAISS, Antônio; Sales, Mauro de Salles Villar. Dicionário Honaiss da Lingua Portuguesa. Rio de Janeiro: Objetiva, 2001 (1 vol.).

SANTOS, Joel Rufino dos. Épuras do social: como podem os intelectuais trabalhar para os pobres. São Paulo: Global, 2004. 
